AperTO - Archivio Istituzionale Open Access dell'Università di Torino

\title{
PLEIOTROPIC EFFECTS OF WHITE WILLOW BARK AND 1,2 DECANEDIOL ON HUMAN ADULT KERATINOCYTES
}

\section{This is the author's manuscript}

Original Citation:

Availability:

This version is available http://hdl.handle.net/2318/1651129

since 2019-01-30T19:12:41Z

Published version:

DOI:10.1159/000481690

Terms of use:

Open Access

Anyone can freely access the full text of works made available as "Open Access". Works made available under a Creative Commons license can be used according to the terms and conditions of said license. Use of all other works requires consent of the right holder (author or publisher) if not exempted from copyright protection by the applicable law. 


\title{
PLEIOTROPIC EFFECTS OF WHITE WILLOW BARK AND 1,2 DECANEDIOL ON HUMAN ADULT KERATINOCYTES.
}

\author{
Eleonora Bassino ${ }^{1}$, Franco Gasparri ${ }^{2}$ \& Luca Munaron ${ }^{1}$ \\ ${ }^{1}$ Department of Life Sciences \& Systems Biology, University of Torino, ${ }^{2}$ Department of Pharmacy (DIFARMA), \\ University of Salerno, Italy.
}

Running title: Effects of white willow bark and 1,2 decanediol on keratinocytes.

Keywords: natural products, keratinocytes, 1,2 decanediol, white willow bark

*Correspondence to:

Luca Munaron, Ph.D.

Dept. Life Sciences \& Systems Biology

University of Torino

Via Accademia Albertina 13

10123 Torino

ITALY

luca.munaron@unito.it 


\begin{abstract}
:
BACKGROUND: Acne vulgaris is a common skin defect, usually occurring during adolescence, but often it can persist in adults leaving permanent face scarring. Acne is usually treated with topic drugs, oral antibiotics, retinoids and hormonal therapies, but medicinal plants are increasingly employed.
\end{abstract}

OBJECTIVE: To investigate the protective role of white willow bark (WWB) and 1,2 decanediol (DD) on the damage caused by Lipopolysaccharides (LPS) on human adult keratinocytes (HaCaT).

METHODS: HaCaT were exposed to LPS alone or in association with WWB and DD. Epidermal viability, metabolic modulation, inflammatory activity, and cell migration were assessed with both common standardized protocols or high-throughput screening systems (HTS).

RESULTS: The pre-incubation of HaCaT with WWB and DD (used separately or in combination) differently prevented the alterations induced by LPS on HaCaT in terms of growth factor release (IGF, EGF, VEGF), cytokine production (IL-1 $\alpha$, IL-6, IL-8), or expression of the transcription factor FOXO-I. Moreover, they partially restore wound repair lowered by LPS.

CONCLUSIONS: These results suggest that both natural compounds were able to differently affect several functions of LPS-stressed keratinocytes suggesting their potential role for prevention of acne vulgaris, without adverse effects. 


\section{INTRODUCTION}

Human skin is a complex organ which plays many functions such as regulation of water/electrolyte homeostasis, defense against physical, chemical and biological factors and secretion [1-2]. Skin is formed by different cell types in a well-structured interplay among epidermal and follicular keratinocytes, sebocytes, melanocytes, dermal papilla cells, fibroblasts, endothelial cells and sweat gland cells [3]. It is a target for hormones and an endocrine gland, whose physiology is influenced by environmental, genetic or nutritional factors. The primary mechanism of skin cell alteration is based on oxidative stress processes [4].

Acne vulgaris is a very common defect, tipically associated with adolescence, but sometimes leading to permanent scarring on the face in adults. Its complex development involves androgenmediated stimulation of sebaceous gland activity, follicular hyper-keratinization and colonization of Propionibacterium acnes (P. Acnes). Acne is currently treated by the use of local applications, oral antibiotics, retinoids and hormonal therapies: nonetheless, increasing interest is focused on natural plant-derivatives [5]. Some natural compounds (eg. mixtures of phenolic compounds) are recently under investigation as promising drugs for new dermal cosmetics that possess the ability to maintain skin cell renewal elastin and collagen stimulation) [6]. Mixed formulations (kaempferol and either erythromycin or clindamycin; quercetin and either erythromycin or clindamycin) synergically inhibit antibiotic resistant P. acnes growth [7]. The European Pharmacopoeia defines White Willow Bark (WWB) as the whole or fragmented dried bark of young branches or dried pieces of current year twigs from various species of the genus Salix [8]. WWB has been used as a traditional medicine for the treatment of fever, pain, and inflammation [9]. Salicin, the major constituent of WWB extract, is metabolized to salicylic acid in vivo and plays anti-inflammatory effects; moreover, other ingredients in the extracts include other salicylates as well as polyphenols and flavonoids, that could play prominent roles in the therapeutic efficacy [10]. WWB suppresses inflammatory molecules and reduces oxidative stress in human endothelial cells [11-12]. In vitro 
and in vivo studies evidenced that the anti-inflammatory activity of WWB is associated with the downregulation of the inflammatory mediators TNF- $\alpha$ and NF-KB [13]. A work by Gopaul et al. (2010) described the ability of salicin to reduce the visible signs of skin aging when applied topically, thus showing anti-aging capabilities [14].

Among natural compounds involved in the regulation of skin homeostasis, 1,2 alkanediols display several properties (high water solubility and effectiveness as a solvent) that allow their use as moisturizing compounds in dermal cosmetic field [15-16]. Indeed, their bacteriostatic and fungistatic activity decreased the amount of conventional preservatives inside cosmetic formulations. Generally, the antimicrobial effect of 1,2-alkanediols increase with the length of their carbon chain, with 1,2-decanediol having a MIC value of $<1 \%$, which is 10 -fold lower than that of 1,2-octanediol [17]. A recent study reported the effects of five 1,2-alkanediols on skin irritation potentials [18], that represent an important factor for determining the usefulness of 1,2-alkanediols. Here we tested the effects of WWB and 1,2-decanediol (DD), used alone or in combination, on human adult keratinocytes (HaCaT) stressed by LPS. Moreover, we investigated a possible role of DD not only as a moisturizing agent, but also as bioactive molecule on epidermal layers.

\section{Materials and methods}

\section{Drugs}

Lipopolysaccharides from Escherichia coli (LPS) were purchased from Sigma-Aldrich. 1,2 decanediol (DD) is a diol monomer, solid and soluble only in cosmetic esters, and acts as an antiacne agent and antiperspirant (Symrise, Holzminden, Germany). Willow bark extract (WWB) is an extract of the white bark of Salix Alba that is standardized for its salicin content (Euromed (Barcellona, Spain). DD and WWB were prepared in $0.001 \%$ DMSO (see table I for concentrations). 


\section{Cell Cultures}

Human Adult Keratinocyte cell line (HaCaT) was obtained from Cell Line Services (CLS Cell Lines Service, Germany). HaCaT were grown in Dulbecco's Modified Eagle medium (DMEM) with 10\% FCS and 1\% antibiotic/antimycotic (Invitrogen, Grand Island, NY, USA).

\section{Cell viability}

HaCaT were seeded in 96-well plates (5000 cells/well). Cells were treated as indicated in Table II. After 24 hrs cell viability was evaluated by the CellTiter $96{ }^{\circledR}$ AQueous Non-Radioactive Cell Proliferation Assay (Promega, Madison, WI, USA), using 3-(4,5-dimethylthiazol-2-yl)-5-(3carboxymethoxyphenyl)-2-(4-sulfophenyl)-2H tetrazolium, inner salt (MTS). MTS conversion into the aqueous soluble formazan product is accomplished by dehydrogenase enzymes found in metabolically active cells. Formazan product was measured with a FilterMax F5 Microplate reader (Molecular Devices, US) at $490 \mathrm{~nm}$, as absorbance is directly proportional to the number of viable cells.

\section{Enzyme-linked immunosorbent assay (ELISA)}

Pro-inflammatory cytokines (IL-1 $\alpha$, IL-6 and IL-8), growth factors (VEGF, EGF, IGF-I), metabolic markers (keratin 16) and transcriptional factors (FOXO-I) were quantified in cell lysates or medium by enzyme-linked immunosorbent assay (ELISA) using commercially available kits (Sigma ELISA kit, Invitrogen ELISA Kit). Briefly, $100 \mu \mathrm{L}$ of medium or cell lysate were incubated into an antibody-coated 96-well plate at room temperature for $2,5 \mathrm{hrs}$. The wells were washed four times with wash buffer solution. Then $100 \mu \mathrm{L}$ of primary anti-human antibody was added and the samples were again incubated for $1 \mathrm{~h}$ at room temperature. The plate was washed four times, $100 \mu \mathrm{L}$ of streptavidin-peroxidase conjugated was applied for $1 \mathrm{~h}$ at room temperature. After a final washing, $100 \mu \mathrm{L}$ tetramethylbenzidine substrate was added and allowed to develop for 30 ' in the dark at room temperature. After stopping the reaction with $50 \mu \mathrm{L}$ stop solution containing citric acid $2.0 \mathrm{mmolL}^{-}$ 
1, absorbance was read at $450 \mathrm{~nm}$ with a F5 FilterMax microplate reader 550 (Molecular Devices, US). Sample concentration was calculated from the standard curve.

\section{Cytosolic and nuclear protein extraction for FOXO-I quantification}

HaCaT were grown to $80 \%$ confluence. Afterwards, cells were scraped using fresh PBS, collected into an appropriate conical tube and centrifuged ( $5^{\prime}$ at $450 \mathrm{x} g$ ). Then the supernatant was discarded and $1 \mathrm{~mL}$ of Lysis Buffer (10 mM Tris $\mathrm{HCl}, \mathrm{pH} 7.5,2 \mathrm{mM} \mathrm{MgCl} 2,3 \mathrm{mM} \mathrm{CaCl} 2,0.3 \mathrm{M}$ Sucrose, including DTT and Protease Inhibitors) was added to $200 \mu \mathrm{L}$ of packed cell volume (PCV) for 15 minutes. Suspended cells were centrifuged for 5 minutes at $420 \mathrm{x} g$. Pellet of packed cells was resuspended in $400 \mu \mathrm{L}(2 \mathrm{X}$ PCV) Lysis Buffer and fragmented using a syringe with a narrowgauge. The disrupted cells in suspension were centrifuged for $20 \mathrm{~min}$ at $10,000 \mathrm{x} g$. The supernatant was transferred into a fresh tube and this fraction corresponds to the cytoplasmic fraction. The pellet was resuspended in $140 \mu$ extraction buffer (20 mM HEPES, pH 7.9, with $1.5 \mathrm{mM} \mathrm{MgCl}_{2}$, $0.42 \mathrm{M} \mathrm{NaCl}, 0.2 \mathrm{mM}$ EDTA, 25\% (v/v) Glycerol added with $1.5 \mu \mathrm{L}$ of the $0.1 \mathrm{M}$ DTT solution and $1.5 \mu \mathrm{L}$ of the Protease Inhibitor Cocktail) and centrifuged for 5 minutes at $20,000 \times g$. The resulting supernatant is the nuclear protein extract. It is finally collected to a clean tube and analyzed with FOXO-1 ELISA assay.

\section{Scratch wound healing}

HaCaT were seeded in 24 multi-well plates and cultured to confluence. A scratch was made in the confluent monolayer with a plastic disposable pipette tip $(10 \mu \mathrm{l})$. Debris was removed from the culture by gently washing with sterile PBS. Hereafter, HaCaT were cultured in DMEM 10\%, and treated with $10 \mu \mathrm{g} / \mathrm{ml}$ LPS, DD, WWB alone or in association for $24 \mathrm{hrs}$. Experiments were performed using a Nikon T-E microscope (4x objective). Cells were kept at $37^{\circ} \mathrm{C}$ and $5 \% \mathrm{CO}_{2}$ for all experiments. Photos were taken every 4 hrs using Metamorph software. Cell migration was measured with Image J software (Rasband, W.S., ImageJ, U. S. National Institutes of Health, 
Bethesda, Maryland, USA). At least three fields for each condition were analyzed in each independent experiment.

\section{Statistical analysis}

Statistical significance of all experiments was evaluated by GraphPad software (Synergy Software, USA). The Dunnet's multi-comparison test was chosen because five biological replicates were done for each condition in each experiment and they were not normally distributed. Five technical replicates were performed for each experimental condition; three biological replicates were performed for each experimental condition: $\mathrm{N}=3$.

Results with $p$-values $<0.05$ were considered statistically significant: $* \mathrm{p}<0.05 ; * * \mathrm{p}<0.01$; $* * * \mathrm{p}<0.001$ 


\section{RESULTS}

WWB and DD affect cell viability of human adult keratinocytes treated with LPS.

In order to set a suitable pattern of LPS concentrations to be tested, we performed a preliminary dose-response curve of HaCaT viability. Lower concentrations of LPS (up to $10 \mu \mathrm{g} / \mathrm{ml}$ for $24 \mathrm{hrs}$ ) did not affect $\mathrm{HaCaT}$ number, while a higher dose $(25 \mu \mathrm{g} / \mathrm{ml}$ for $24 \mathrm{hrs})$ significantly reduced cell viability (Fig. 1A). Based on these results, we first evaluated the effect of WWB and DD (separately or as WWB/DD complex) on cells treated with $10 \mu \mathrm{g} / \mathrm{ml}$ LPS (ineffective dose). High concentrations of DD significantly affected cell viability, while lower doses were ineffective (Fig. 1B). WWB (B concentration) significantly affected cell viability (Fig. 1C). The association of both compounds (WWB/DD complex) significantly reduced cell viability when added both at higher doses in HaCaT treated with $10 \mu \mathrm{g} / \mathrm{ml}$ LPS (Fig. 1F). Both compounds failed to prevent the cytotoxicity induced by $25 \mu \mathrm{g} / \mathrm{ml}$ LPS both separately (Fig. 1D, E) and in complex (Fig. 1G). For the following tests we chose the lowest, no cytotoxic concentrations of the natural compounds and we test their effects on $10 \mu \mathrm{g} / \mathrm{ml}$ LPS.

\section{Release of EGF, IGF-I and KRT16.}

$10 \mu \mathrm{g} / \mathrm{ml}$ LPS promoted a significant EGF release by $\mathrm{HaCaT}$ (24 hrs) (Fig. 2Ai). DD and WWB, both separately and in complex, significantly prevented LPS-induced EGF release (Fig. 2Aii). The same trend was observed on IGF-1 release (Fig. 2Bi and ii). Finally, the treatment with $10 \mu \mathrm{g} / \mathrm{ml}$ LPS slightly, but not significantly, increased KRT16 production (Fig. 2Ci), an effect slightly prevented by DD (Fig. 2Cii). 


\section{FOXO-I distribution}

Incubation with $10 \mu \mathrm{g} / \mathrm{ml}$ LPS (24 hrs) drastically enhanced cytosolic expression of FOXO-I (Fig. 2Di), this effect was prevented by incubation with DD and WWB, both separately or in combination (Fig. 2Dii).

\section{Modulation of wound closure and anti-inflammatory role of WWB and DD}

To evaluate the role of both compounds in the wound healing rate of $\mathrm{HaCaT}$, we first examined their ability to modulate cell motility employing an established in vitro scratch wound healing assay. Wound closure was evaluated by observing the re-populated area between the wound margins at different time intervals (0-24 hrs) after the lesion. The wound monitoring showed that untreated cells (DMEM 10\%) followed the physiological healing process, reaching approximately $65 \%$ of closure at $24 \mathrm{hrs}$ after injury (Fig. 3A, Bi). $10 \mu \mathrm{g} / \mathrm{ml}$ LPS (24 hrs) drastically reduced wound-closure percentage, reaching approximately $35 \%$. This effect was prevented by both DD and WWB applied separately (Fig. 3A, Bii). Application of $10 \mu \mathrm{g} / \mathrm{ml}$ LPS reduced VEGF production in scratched keratinocytes (Fig. 3Ci). DD and WWB/DD complex prevented the LPS effect, while WWB resulted uneffective (Fig 3Cii). Skin wounding and inflammatory responses involve cytokines that exert inhibitory activity on human keratinocyte growth. We investigated the effects of DD and WWB both separately and in association on cytokine production (IL-1 $\alpha$, IL-6 and IL-8) by $\mathrm{HaCaT}$ upon treatment with LPS.

Incubation with $10 \mu \mathrm{g} / \mathrm{ml}$ LPS (24 hrs) promoted the release of IL-8, IL-1 $\alpha$ and IL-6 (Fig. 3 Di, Ei and Fi). The lowest doses of DD and WWB, separately or in combination, did not prevent IL-1 $\alpha$ production (Fig. 3Eii); conversely, WWB and WWB/DD were significantly effective on IL-6 and IL-8 release, while DD induced a non significant protective activity (Fig. 3Dii, Fii). 


\section{CONCLUSIONS}

Acne is a multifactorial disease based on an alteration in the pattern of keratinization within the pilosebaceous follicles resulting in comedo formation, an increase in sebum production which is influenced by androgens, the proliferation of P. Acnes, and the development of perifollicular inflammation [19-20]. New commercially available formulations and drugs for skin treatment are increasingly introduced. Evidences suggest a potential beneficial activity of plant-derived phenolic compounds obtained either by the diet or through skin application, indeed, they can alleviate symptoms and inhibit the development of various skin disorders. Recently, a novel face compact cream (FCC) containing a new patented formulation (including both white willow bark extract and 1,2 decanediol) was developed to provide acne patients with cosmetic camouflage for their lesions and to have beneficial effects on the multifactorial components of the disease [21]. Here we tested the role of both compounds on adult keratinocytes stressed with LPS. Both compounds (used alone or in combination) counteracted LPS effects, reducing growth factor and cytokine production. They reduced EGF expression altered by the treatment with LPS. This is interesting because several studies report the alteration of EGF signaling during acne associated with the use of anticancer agents (eg: EGFR inhibitors). Acneiform eruptions are a common adverse reaction to EGFR inhibition and can be treated with traditional acne therapy [22]. Similarly, WWB/DD complex significantly prevented IGF-I production induced by LPS. During puberty, IGF-I signaling may have a causal role in pathogenesis of acne by influencing adrenal and gonadal androgen metabolism that was reported to be an inducer of sebum production through sterol response element-binding proteins [23-24]. Recently, the involvement of IGF-1, but not androgens, has been suggested in acne pathogenesis [25]. A relevant IGF-1-dependent mechanism that increases androgen receptor (AR) signaling involves the metabolic transcription factor FOXO-I. FOXO-I is proposed to be the key to understand the link between genetic and environmental factors in acne. Nuclear FOXO-I functions as an androgen receptor co-suppressor it regulates the activity of most important target genes involved in the pathogenesis of acne [26]. All growth factors or acneigenic stimuli mimicking 
growth factor signaling might lead to the reduction of the nuclear content of FOXO-I. In the present study we observed that WWB and DD, used separately or in combination, significantly decrease FOXO-I cytosolic/nuclear ratio. Both WWB and DD slightly but not significantly prevented KRT16 expression after LPS treatment. KRT16, as well as KRT6 and KRT17, is considered a stress keratin chronically expressed in human pre-malignant hyperproliferative epithelium [27]. Finally, we tested the role of natural compounds in the modulation of keratinocyte migration and in the production of pro-inflammatory cytokines. Li M. et al., (2015) reported the ability of LPS to reduce keratinocyte migration in a diabetes-like microenvironment [28]. Here we observed that both compounds markedly promoted HaCaT migration and to enhance artificial wound closure compromised by LPS treatment, an effect related to their ability to sustain VEGF production. Cellfree extracts of $P$. Acnes significantly stimulate secretion of interleukins (IL-8 and IL-6) in SZ95 sebocytes [29], and promotes IL-8 secretion by interacting with Toll-like receptor 2 (TLR-2) [30]. IL-6 is a pleiotropic cytokine that plays a pivotal role in host defense, immune response regulation, hematopoiesis and inflammation [31]. SNPs in IL-6 gene have been identified and associated with several diseases [32-33]. However, there are relatively few studies on IL-6 gene polymorphism in Acne patients. It has been recently reported that the IL- 6 and IL- $1 \alpha$ gene promoter polymorphisms are associated with the pathogenesis of acne vulgaris [34]. IL-1 $\alpha$ has been widely studied in inflammation and is considered to affect the pathogenesis of acne [35]; it also contributes to paracrine signaling between keratinocytes and fibroblasts during wound healing. WWB and DD differently affect cytokine production. Both compounds failed to counteract IL-1 $\alpha$ release increased by LPS treatment. Conversely, WWB alone or WWB/DD complex significantly reduced IL-6 and IL-8 release, while only a slight effect could be observed upon stimulation with DD alone.

In conclusion, taken together, our results show the ability of both natural compounds to affect different functions of LPS-stressed keratinocytes. 


\section{Conflict of interest}

The authors have declared that there is no conflict of interest.

\section{Acknowledgements}

E.B. designed the research study, performed the research, analyzed the data and wrote the paper.

F.G. contributed essential reagents or tools and designed the research study.

L.M. designed the research study, analyzed the data, wrote the paper and contributed essential reagents or tools.

This study was funded by Rottapharm Madaus. 


\section{REFERENCES}

1. Feingold KR. J Invest Dermatol. Innate immunity stimulates permeability barrier homeostasis.. 2013;133:1925-7.

2. Boury-Jamot M, Daraspe J, Bonté F, Perrier E, Schnebert S, Dumas M, Verbavatz JM. Handb Exp Pharmacol. Skin aquaporins: function in hydration, wound healing, and skin epidermis homeostasis. 2009;190:205-17.

3. Zouboulis CC. Hormones (Athens). The human skin as a hormone target and an endocrine gland. 2004;3:9-26.

4. Puizina-Ivi'c, N. Skin aging. Acta Dermatovenerol. Alp. Pannonica Adriat. 2008;17:47-54.

5. Decker A, Graber EM. J Clin Aesthet Dermatol. Over-the-counter Acne Treatments: A Review. 2012;5:32-40. 2012.

6. Ribeiro AS, Estanqueiro M, Oliveira MB, Sousa Lobo JM. Cosmetics. Main benefits and applicability of plant extracts in skin care products. 2015;2:48-65.

7. Lim YH, Kim IH, Seo JJ. J Microbiol. In vitro activity of kaempferol isolated from the Impatiens balsamina alone and in combination with erythromycin or clindamycin against Propionibacterium acnes. 2007;45:473-7.

8. Nahrstedt A, Schmidt M, Jäggi R, Metz J, Khayyal MT. Wien Med Wochenschr. Willow bark extract: the contribution of polyphenols to the overall effect. $2007 ; 157: 348-51$.

9. Hedner T, Everts B. Clin Rheumatol. The early clinical history of salicylates in rheumatology and pain. 1998; 17:17-25.

10. Schmid B, Kotter I, Heide L. Eur J Clin Pharmacol. Pharmacokinetics of salicin after oral administration of a standardised willow bark extract. 2001; 57: 387-91.

11. Freischmidt A, Jürgenliemk G, Kraus B, Okpanyi SN, Müller J, Kelber O, Weiser D, Heilmann J. Phytomedicine. Contribution of flavonoids and catechol to the reduction of ICAM-1 expression in endothelial cells by a standardised Willow bark extract. 2012; 19:245-52.

12. , Matsumoto M, Robida-Stubbs S, Okuno A, Goto M, King GL, Blackwell TK, Makino T. Free Radic Biol Med. Willow bark extract increases antioxidant enzymes and reduces oxidative stress through activation of Nrf2 in vascular endothelial cells and Caenorhabditis elegans. 2013;65:1506-15.

13. Shara M, Stohs SJ. Phytoter Res. Efficacy and Safety of White Willow Bark (Salix alba) Extracts. 2015;29:1112-6. 
14. Hiroya, O. Applications of antibacterial 1,2-alkanediol to cosmetics. Fragrance J. 2006;34:3438.

15. Pillai R, Schmaus G, Pfeiffer A, Lange S. Trunet A. Cosmetics \& Toiletries Magazine. 1,2Alkanediols for cosmetic preservation. 2008;123:53-64.

16. Roden, K. The preservative effect of 1,2-alkanediols. 20th FSCC Conference (2009).

17. Lee E, An S, Cho SA, Yun Y, Han J, Hwang YK, Kim HK, Lee TR. Int J Cosmet Sci. 2011; $33: 421-5$.

18. Winston MH, Shalita AR. Pediatr Clin North Am. Acne Vulgaris: pathogenesis and treatment 1991;38:889-903.

19. Tanghetti EA. The Role of Inflammation in the Pathology of Acne. J Clin Aesthet Dermatol. $2013 ; 6: 27-35$.

20. DeWitt CA, Siroy AE, Stone SP. J Am Acad Dermatol. Acneiform eruptions associated with epidermal growth factor receptor-targeted chemotherapy. 2007;56:500-5.

21. Monfrecola G, Cacciapuoti S, Capasso C, Delfino M, Fabbrocini G. Clin Cosmet Investig Dermatol. Tolerability and camouflaging effect of corrective makeup for acne: results of a clinical study of a novel face compact cream. 2016;9:307-313.

22. DeWitt CA DeWitt CA, Siroy AE, Stone SP. J Am Acad Dermatol. Acneiform eruptions associated with epidermal growth factor receptor-targeted chemotherapy. 2007;56:500-5.

23. Assaf HA, Abdel-Maged WM, Elsadek BE, Hassan MH, Adly MA, Ali SA. Dis Markers. Survivin as a Novel Biomarker in the Pathogenesis of Acne Vulgaris and Its Correlation to Insulin-Like Growth Factor-I. 2016:7040312.

24. Rahaman SM, De D, Handa S, Pal A, Sachdeva N, Ghosh T, Kamboj P. J Am Acad Dermatol. Association of insulin-like growth factor (IGF)-1 gene polymorphisms with plasma levels of IGF-1 and acne severity. 2016;75:768-73.

25. Melnik BC. Linking diet to acne metabolomics, inflammation, and comedogenesis: an update Clin Cosmet Investig Dermatol. 2015;8:371-88.

26. Li J, Al-Azzawi F. Mechanism of androgen receptor action. Maturitas. 2009;63:142-148.

27. Zhussupbekova S, Sinha R, Kuo P, Lambert PF, Frazer IH, Tuong ZK. EBioMedicine. A Mouse Model of Hyperproliferative Human Epithelium Validated by Keratin Profiling Shows an Aberrant Cytoskeletal Response to Injury. 2016;9:314-23. 
28. Li M, Zhao Y, Hao H, Dai H, Han Q, Tong C, Liu J, Han W, Fu X. Int J Low Extrem Wounds. Mesenchymal stem cell-conditioned medium improves the proliferation and migration of keratinocytes in a diabetes-like microenvironment. 2015;14:73-86.

29. Huang YC, Yang CH, Li TT, Zouboulis CC, Hsu HC. Life Sci. Cell-free extracts of Propionibacterium acnes stimulate cytokine production through activation of p38 MAPK and Toll-like receptor in SZ95 sebocytes. 2015;139:123-31.

30. Grange PA, Chéreau C, Raingeaud J, Nicco C, Weill B, Dupin N, Batteux F. PLoS Pathog. Production of superoxide anions by keratinocytes initiates P. acnes-induced inflammation of the skin. 5:e1000527.

31. Kishimoto T. Blood. The biology of interleukin-6. 1989;74:1-10.

32. Foster CB, Lehrnbecher T, Samuels S, Stein S, Mol F, Metcalf JA, Wyvill K, Steinberg SM, Kovacs J, Blauvelt A, Yarchoan R, Chanock SJ. Blood. An IL6 promoter polymorphism is associated with a lifetime risk of development of Kaposi sarcoma in men infected with human immunodeficiency virus. 2000;96:2562-7.

33. Ghazouani L, Abboud N, Ben Hadj Khalifa S, Added F, Ben Khalfallah A, Nsiri B, Mediouni M, Mahjoub T. Ann Saudi Med. $-174 \mathrm{G}>\mathrm{C}$ interleukin-6 gene polymorphism in Tunisian patients with coronary artery disease. 2011;31:40-4.

34. Younis S, Javed Q. Arch Dermatol Res. The interleukin-6 and interleukin-1A gene promoter polymorphism is associated with the pathogenesis of acne vulgaris. 2015;307:365-70.

35. Ingham E, Eady EA, Goodwin CE, Cove JH, Cunliffe WJ. J Invest Dermatol. Pro-inflammatory levels of interleukin-1 alpha-like bioactivity are present in the majority of open comedones in acne vulgaris. 1992;98:895-901. 


\section{FIGURE LEGENDS}

\section{Figure 1. WWB and DD exert protective effects on HaCaT treated with LPS.}

A) $25 \mu \mathrm{g} / \mathrm{ml}$ LPS significantly reduced cell viability compared to untreated cells.

B) The highest dose of DD (A) significantly reduced cell viability of $\mathrm{HaCaT}$ treated with $10 \mu \mathrm{g} / \mathrm{ml}$ LPS. The other concentrations slightly but not significantly reduced cell viability.

C) The intermediate dose of WWB (B) significantly reduced cell viability of HaCaT treated with 10 $\mu \mathrm{g} / \mathrm{ml}$ LPS. The other concentrations were ineffective.

D) The highest dose of DD (A) significantly reduced cell viability of $\mathrm{HaCaT}$ treated with $25 \mu \mathrm{g} / \mathrm{ml}$ LPS. The other concentrations were ineffective.

E) All the concentrations of WWB (A-C) were ineffective on cell viability of $\mathrm{HaCaT}$ treated with $25 \mu \mathrm{g} / \mathrm{ml}$ LPS.

F) The combination of the highest doses of WWB/DD (A) significantly reduced cell viability of HaCaT treated with $10 \mu \mathrm{g} / \mathrm{ml}$ LPS.

G) All the concentrations of WWB/DD were ineffective on cell viability of HaCaT treated with 25 $\mu \mathrm{g} / \mathrm{ml}$ LPS. $D D(A: 5.2 \mathrm{mg} / \mathrm{ml}, B: 26 \mu \mathrm{g} / \mathrm{ml}, C: 13 \mu \mathrm{g} / \mathrm{ml}) ; W W B(A: 520 \mu \mathrm{g} / \mathrm{ml}, B: 260 \mu \mathrm{g} / \mathrm{ml}, \quad C: 130$ $\mu \mathrm{g} / \mathrm{ml}), W W B / D D(A / A: 5.2 m g / m l+520 \mu g / m l ; B / B: 26 \mu g / m l+260 \mu g / m l ; C / C: 13 \mu g / m l+130$ $\mu g / m l)$.

Figure 2. The lowest concentrations of WWB and DD differently affect EGF, IGF-I and KRT16 production and FOXO-I translocation.

A) $\mathrm{HaCaT}$ were stimulated with $10 \mu \mathrm{g} / \mathrm{ml}$ LPS alone (i) or in association with the lowest concentrations (C) of WWB and DD (ii). Supernatant was collected after 24 hrs and EGF secretion 
was quantified with ELISA test. 10 $\mathrm{g} / \mathrm{ml}$ LPS increased EGF production (i). WWB and DD (alone or in association) significantly reduced EGF production increased by LPS treatment (24 hrs) (ii).

B) $\mathrm{HaCaT}$ were stimulated with $10 \mu \mathrm{g} / \mathrm{ml}$ LPS used alone (i) or in association with the lowest concentrations (C) of WWB and DD (ii). Supernatant was collected after 24 hrs and IGF-I secretion was quantified with ELISA test. $10 \mu \mathrm{g} / \mathrm{ml}$ LPS increased IGF-I production after $24 \mathrm{hrs}$ of treatment (i). WWB/DD complex significantly reduced IGF-I production affected by LPS (24 hrs) (ii).

C) $\mathrm{HaCaT}$ were stimulated with $10 \mu \mathrm{g} / \mathrm{ml}$ LPS used alone (i) or in association with the lowest concentrations (C) of WWB and DD (ii). Cytosolic extract was collected after 24 hrs and KRT16 secretion was quantified with ELISA test. $10 \mu \mathrm{g} / \mathrm{ml}$ LPS slightly but not significantly increased KRT16 production (i). WWB or DD used alone or in combination did not significantly modify KRT16 production (24 hrs) (ii).

D) $\mathrm{HaCaT}$ were stimulated with $10 \mu \mathrm{g} / \mathrm{ml}$ LPS used alone (i) or in association with the lowest concentrations (C) of WWB and DD (ii). After 24 hrs cytosolic and nuclear FOXO-I extracts were obtained and quantified with ELISA test. $10 \mu \mathrm{g} / \mathrm{ml}$ LPS increased cytosolic/nuclear ratio of FOXO-I (i). Both WWB and DD used alone or in association (lowest dose) significantly reduced FOXO-I ratio (24 hrs) (ii). $D D(C: 13 \mu \mathrm{g} / \mathrm{ml})$; $W W B(C: 130 \mu \mathrm{g} / \mathrm{ml}), W W B / D D(C / C: 13 \mu \mathrm{g} / \mathrm{ml}+130 \mu \mathrm{g} / \mathrm{ml})$.

Figure 3. The lowest concentrations of WWB and DD differentially regulate wound closure and pro-inflammatory cytokine production.

A) Representative micrograph of keratinocytes directly ( $0 \mathrm{hrs}$ ) or $24 \mathrm{hrs}$ after scraping (original magnification 4x).

B) $\mathrm{HaCaT}$ cells were scratched and stimulated with $10 \mu \mathrm{g} / \mathrm{ml}$ LPS used alone or in association with WWB and DD. Percentage of wound-closure is shown as mean \pm SEM of 3 independent experiments. 
C) HaCaT were scratched and stimulated with $10 \mu \mathrm{g} / \mathrm{ml}$ LPS used alone or in presence of WWB and DD (alone or in complex, both at the lowest concentration). Supernatant was collected at 24 hrs after scraping and VEGF production was quantified with ELISA test. $10 \mu \mathrm{g} / \mathrm{ml}$ LPS significantly reduced VEGF production (i). DD alone or in complex with WWB complex significantly prevented the VEGF reduction (ii).

D) HaCaT were stimulated with $10 \mu \mathrm{g} / \mathrm{ml}$ LPS used alone or in presence of WWB and DD (alone or in complex, both at the lowest concentration). Supernatant was collected after $24 \mathrm{hrs}$ and IL-8 secretion was quantified with ELISA test. $10 \mu \mathrm{g} / \mathrm{ml}$ LPS significantly increased IL-8 production (i). WWB alone or WWB/DD complex significantly prevented this effect (ii).

E) $\mathrm{HaCaT}$ were stimulated with $10 \mu \mathrm{g} / \mathrm{ml}$ LPS used alone (i) or in presence (ii) of WWB and DD (used alone or in complex, both at the lowest concentration). Supernatant was collected after $24 \mathrm{hrs}$ and IL- $1 \alpha$ secretion was quantified with ELISA test. $10 \mu \mathrm{g} / \mathrm{ml}$ LPS significantly increased Il$1 \alpha$ release (i). DD and WWB alone or in association did not modify this effect (ii).

F) $\mathrm{HaCaT}$ were stimulated with $10 \mu \mathrm{g} / \mathrm{ml}$ LPS used alone (i) or in association (ii) to WWB and DD (alone or in complex, both at the lowers concentration). Supernatant was collected after $24 \mathrm{hrs}$ and IL-6 secretion was quantified with ELISA test. $10 \mu \mathrm{g} / \mathrm{ml}$ LPS significantly increased IL-6 release (i). WWB alone or in association to DD significantly prevented this effect (ii). DD (A:5.2mg/ml, B:26 $\mu \mathrm{g} / \mathrm{ml}, \mathrm{C}: 13 \mu \mathrm{g} / \mathrm{ml}) ; \mathrm{WWB}(\mathrm{A}: 520 \mu \mathrm{g} / \mathrm{ml}, \mathrm{B}: 260 \mu \mathrm{g} / \mathrm{ml}, \mathrm{C}: 130 \mu \mathrm{g} / \mathrm{ml}), \mathrm{DD} / \mathrm{WWB}(\mathrm{C} / \mathrm{C}$ : $13 \mu \mathrm{g} / \mathrm{ml}+130 \mu \mathrm{g} / \mathrm{ml})$ 